TI 2011-114/3

Tinbergen Institute Discussion Paper

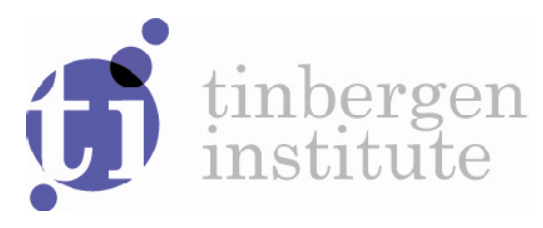

\title{
Commuter Effects on Local Labour Markets: \\ A German Modelling Study
}

Giovanni Russo*

Federico Teschi***

Aura Reggiani***

Peter Nijkamp*

* Faculty of Economics and Business Administration, VU University Amsterdam, and Tinbergen Institute, The Netherlands;

** University of Bologna, Italy; 
Tinbergen Institute is the graduate school and research institute in economics of Erasmus University Rotterdam, the University of Amsterdam and VU University Amsterdam.

More TI discussion papers can be downloaded at http://www.tinbergen.nl

Tinbergen Institute has two locations:

Tinbergen Institute Amsterdam

Gustav Mahlerplein 117

1082 MS Amsterdam

The Netherlands

Tel.: +31(0)205251600

Tinbergen Institute Rotterdam

Burg. Oudlaan 50

3062 PA Rotterdam

The Netherlands

Tel.: +31(0)10 4088900

Fax: $+31(0) 104089031$

Duisenberg school of finance is a collaboration of the Dutch financial sector and universities, with the ambition to support innovative research and offer top quality academic education in core areas of finance.

DSF research papers can be downloaded at: http://www.dsf.nl/

Duisenberg school of finance

Gustav Mahlerplein 117

1082 MS Amsterdam

The Netherlands

Tel.: +31(0)20 5258579 


\title{
Commuter Effects on Local Labour Markets: A German Modelling Study
}

\author{
Giovanni Russo $^{*}$, Federico Tedeschi** ${ }^{* *}$ Aura Reggiani ${ }^{* *}$, Peter Nijkamp ${ }^{*}$ \\ *VU, FEWEB, De Boelelaan 1105, 1081 HV Amsterdam, the Netherlands \\ ** University of Bologna, Department of Economics, Faculty of Statistics, Piazza Scaravilli 2, \\ 40126 Bologna, Italy \\ • Corresponding author, email: federicotedeschi80@gmail.com
}

\begin{abstract}
This paper offers an exploratory investigation of the effects of inbound commuter flows on employment in regional labour markets in Germany. For this purpose, we distinguish three main channels that may transmit the effects concerned: a crowding-out mechanism, and two labour demand effects, namely, an aggregate demand effect and a positive externality on vacancy creation. To this end, we develop a stepwise commuting impact model. Our results bring to light that, on the whole, commuter flows have a positive and robust effect on both employment and the number of jobs in the receiving labour market districts, but a distinctly negative effect on the share of jobs filled by resident workers. We then interpret the implications of our results, and, finally, we suggest ways in which the analysis could be improved and expanded.
\end{abstract}

Pn372grftar 


\section{Introduction}

There is a dearth of research on the effects of commuter flows on the labour market of the receiving region. In fact, commuters are usually assumed to be attracted to regions with relatively high wages, thus bringing the wage level down to that prevailing in neighbouring regions. This also seems to hold for Germany, since regional unemployment rates (Juessen and Bayer, 2005) and skill composition (Südekum, 2008) have been found to converge quickly. Rather surprisingly, in regional labour market analyses (both in Germany and elsewhere) it is seldom postulated (and investigated) that commuters might have a positive impact on employment and job creation in the receiving region. This may happen because the availability of commuters may make it easier to fill vacant positions, thus lowering the cost of an open vacancy, and hence generating a positive labour demand externality in the receiving region. This lack of knowledge justifies our empirical analysis. Against this backdrop, the purpose of the paper is to evaluate how flows of commuters affect regional employment. This is both the crux and the novelty of our analysis.

Our empirical analysis will be carried out on a panel data set of regional labour markets: the data used refer to the 439 German NUTS 3 districts, for the period 2000-2005, and are compiled from the IAB (Institut fur Arbeitsmarkt und Berufsforschung) data set.

The structure of the paper is as follows. In Section 2 we provide a brief literature review. In Section 3, we explore the theoretical background. Section 4 describes the data available. Section 5 presents the empirical results. Finally, Section 6 concludes.

\section{Commuting and Labour Market Analysis: a Concise Review}

\subsection{Commuting and regional labour markets}

Commuting is defined as the daily travel between one's place of residence and place of work. The way that working and residential location are determined has been thoroughly and extensively 
analysed at the micro-level in the labour market literature in recent decades. In this framework it is acknowledged that distance (in the geographical sense, as expressed either by kilometres or by travel time) may play a critical role. In fact, employment and wage opportunities may affect residential location choices, since distance from the workplace - and from firms searching for new employees - translates into travel time and costs. This leads to a well-delimited spatial dimension of labour markets determined by the maximum travel-to-work journey ${ }^{1}$ : individual workers may travel beyond this distance but only temporarily, while taking the necessary steps to adjust to the new equilibrium situation (relocation, job change). Hence, the labour supply of a given region is basically given by the population of the region itself and its surrounding area (these workers must be prepared to spend time and money to commute). An example of a model to identify the size of metropolitan areas (and, therefore, the geographical scope of commuting too) can be found in, amongst others, Bode (2006), with an application to West Germany. In his model, the reach of commuting is determined jointly with other forms of interactions and interdependencies, using land prices (as a proxy for spillover effects from metropolitan centres and sub-centres) for assessing the influence of the presence of metropolitan areas and their fringes.

In all questions about accepting (or refusing) job matches and taking a location decision, the typical theoretical framework takes for granted that employees maximize their utility. Commuting distance is then the result of this joint home and workplace choice. A further attempt to integrate labour and land markets can be found in, inter alia, the urban labour economics framework designed by Zenou (2009). Households decide whether to commute or not after considering expected income, relevant transportation costs, and housing prices of any given possible home-job decision. The individual likelihood to commute also varies as a result of socio-demographic characteristics (education, age, gender, and race). Models accounting for such commuting decisions are also proposed in Shields and Swenson (2000) and Hazans (2003). 
At the microeconomic level of analysis, the multiple effects of commuting on relevant economic variables have received due attention. For example, the impact of commuting on individual earnings is analysed in Hazans (2003). In his investigation of earnings effects in the Baltic states, wage returns to commuting are compared, considering the different job/home zones (urban areas, rural areas, and capital cities) in each of these states, separately. In fact, a positive relationship between commuting time and wages can be interpreted as a sign of monopsony (see, for example, Manning, 2003). Basically, since spatial monopsony may arise, wages are not set to be equal to marginal productivity of workers but at a lower level. However, commuters may reduce this gap by requiring compensation for their travel time. This issue is addressed by Rouwendal and van Ommeren (2007), for the Dutch case. They analyse explicit reimbursement schemes for commuting, and find that partial compensation for commuting cost is part of the optimal recruitment policy of a monopsonistic employer.

It is also noteworthy that commuting is found to reduce individual measures of reported wellbeing (Stutzer and Frey, 2004). Hence, commuters do not receive adequate compensation for the time and the stress suffered as a result of their daily journey. This issue is often referred to as the "commuting paradox". The authors then claim that the traditional theory fails to account for the commuting decision, and call for the use of an extended model of human behaviour.

A different analytical setting is the one where micro-behaviour generates macroeconomic effects. For example, Ross and Zenou (2004) investigate the unemployment-wage equilibrium in a model consisting of a mono-centric closed city, where housing prices, location, shirking behaviour, and employment access are included. At the micro-level, commuting time is allowed to negatively affect the time available for leisure at home and, via behavioural substitution, worker's shirking behaviour. They find that either workers segregate over space in terms of effort (workers with a longer commute have a lower level of shirking) or efficiency wages are set to avoid shirking (a hypothesis not supported empirically): commuting is related either to employment or to wages. The 
empirical results suggest that shirking and leisure are complementary: a higher commuting time leads to a lower level of shirking. Since a lower level of shirking implies a lower job destruction rate (being found shirking is assumed to be a cause for firing), they conclude that, in a closed economy, when average commuting time increases, employment does so as well.

The link between the micro- and the macro-level is usually addressed in equilibrium search models. For reviews on this topic, we refer to Elhorst (2003) and Perugini and Signorelli (2007). Traditional labour market theory is characterized by the law of "one price" (with perfect information and wages equal to the worker's marginal productivity). In this setting, commuting is one of the forces that support this law by equalizing wages over space and across regions (hence decreasing inequality). Commuting ensures that labour will flow from regions in a regime of excess labour supply (unemployment) to regions of excess labour demand. However, after this competitive paradigm was challenged by the empirical evidence ${ }^{2}$ (differences in wages appear to hold even among observationally equivalent workers), there was a need for a new theoretical framework concerning job creation and wage determination. Lack of information among the agents and the introduction of a stochastic component in the matching process are taken into account in the search paradigm, thus introducing frictions into the equilibrium framework. For a look at different unemployment equilibrium models in this job-search framework, see Pissarides (2000) and Mortensen (2003).

The importance of job-home distance for workers leads, at the macro-level, to a link between labour market and population dynamics. Such a relationship is addressed, for instance, by Birg (1981), who proposes a model where the density of the population depends on the regional distribution of employment and income, with specific reference to the German case. The job-home decision also implies interregional commuting; and, in an empirical modelling study, Vermeulen and van Ommeren (2004) explicitly account for this phenomenon. These authors allow for

2 For a review on this topic, see Thiel (2005) and Baye et al. (2006). 
dependence between population growth in one region and employment in another region, in an equilibrium framework, by distinguishing between short-run and long-run effects. They find that equilibrium is achieved via adjustment of employment, not of population, and that net migration is dominated by housing market developments, and in the short run is only slightly affected by an increase in general employment. Basically, people do not migrate to a region with a higher demand for jobs, rather they are attracted by the availability of cheaper housing; hence, the labour market tends to react to migration shocks.

Clearly, the firm's location is also to be considered, since distance may also affect the employer's profits, for example, through inter-firm externalities. In this vein, Simpson (1992) develops a labour market model for residential and workplace location choice, where the workplace location is also allowed to depend on the spatial distribution of labour availability. The importance of the spatial aspects of job search, recruiting, job matching, and commuting is emphasized in this study, developing the notion of "spatially systematic search”. Equilibrium models that consider the effects of distance for both sides of markets may also be found in Rossi-Hansberg et al. (2009) and Anas and Xiong (2005), where the location decision of households and firms is allowed to depend on commuting costs and distance-sensitive inter-firm externalities.

Distance may also be considered from different angles: social distance is considered in an equilibrium framework by Diamond (1982) and Lingens and Heining (2006), while the effect on value added of accessibility ${ }^{3}$ (a sort of compound between geographical and social distance, including ease of access to a given area) is analysed by Karlsson et al. (2006) and Östh (2007). Furthermore, specific variables related to distance have been analysed with respect to their impact on the labour market. Examples related to a macroeconomic point of view include migration (Card, 1990; Borjas, 2003), tourism (Guisan and Aguayo, 2001), and the infrastructural system (Delayque, 1969). In particular, as will be seen later, the effects of migration on native employment and wages 
are of particular interest, since, for small distances in open economies, commuting may be an alternative to migration. Basically, households may face the decision whether to commute or to migrate, as outlined by Shields and Swenson (2000) ${ }^{4}$ and Larsen et al. (2008) ${ }^{5}$.

\subsection{Commuting and migration: similar and yet different}

At first sight, the effects of commuting on resident employment could be considered to be similar to the effects of migration on employment in the receiving country. An extensive literature on the labour market effects of migration (mainly on wages and employment) is available. A comprehensive review can be found in Longhi et al. (2009). This strand of the literature has identified three channels through which migration can influence regional wage and employment.

First, migration can be an important source of productivity (and wage) growth, because migrants can transfer knowledge (of the kind embodied in individuals). In particular, on account of their different cultural backgrounds, migrants can spot untapped resources and business opportunities. Second, migration flows increase labour supply. Hence, if they compete with locals for available jobs, migrants may either reduce wages or increase unemployment. On the other hand, complementary effects may also be important, as long as immigrants are given jobs that are refused by natives. And, third, when they generate an increase in consumption and, possibly, public expenditure, they could improve labour market prospects. For example, the effects of migration on employment rates in an equilibrium framework (considering both short-run and long-run effects) are analysed by Epifani and Gancia (2005), who examine the changes in a critical variable (i.e. transport costs) affecting migration. They find that migration from the periphery to the core reduces unemployment disparities in the short run, while increasing them in the long run.

All in all, whether the net effect of migration is beneficial or not for the host country is an

\footnotetext{
$4 \quad$ They propose an expected utility framework for the commuting decision similar to the one proposed in the migration literature.

5 In this paper, when workers receive a job offer from a different region, they must compare three different utilities: refusing; accepting and relocating; accepting and commuting.
} 
empirical issue. This point is addressed by Longhi et al. (2009), in a study where a meta-analysis of the simultaneous effect of migration on employment and wages in the host country is applied ${ }^{6}$. In their framework, shocks in the demand and supply side translate into changes in other relevant variables (such as the price level), and wages and employment react in order to reach a new equilibrium situation. By comparing the existing literature on this topic, they find four different identification strategies: simulation methods; production function models (in these two cases, the parameters of a model need to be estimated); natural experiments (where exogenous shocks in migration are used as instrumental variables); and area approaches (exploiting the fact that immigrants from a given country tend to cluster spatially). The authors underline the differences between short-run and long-run effects (which also depend on how firms react to immigration, and on how much migration attracts new immigrants), local and national effects, and previous immigrants and natives. They also highlight how results change depending on the time and the country concerned (calling for further investigation of the possible determinants of the reaction to immigration shocks ${ }^{7}$ ) and the model specification adopted ${ }^{8}$, and on how results may be affected by possible sources of bias (outward migration of natives and immigration-driven changes in the production and trade system). They find an overall small negative impact on both wages and on employment (the second effect also depending on the first, since higher wage flexibility reduces the negative employment effect). A greater short-run effect is found on local labour markets (but its magnitude is sensitive to the scale of the labour market), while long-run effects are higher for the national ones.

However, as emphasized by Shields and Swenson (2000), the similarities between commuting and migration cannot be pushed too far: while immigrants stay in the host country for a continuous

\footnotetext{
$6 \quad$ Other social and economic externalities of immigration, such as the effects on internal migration, productivity gains, and exports, are also discussed in their study.

Among these, they include the characteristics of labour markets, firms and immigrants themselves, land and housing prices, openness, and the spatial connectedness of the hosting nation.

8

In particular, they focus on the differences between $O L S$ and $I V$ estimates, and on whether labour market segmentation (by occupation, education, skill, gender, geography) is controlled for or not.
} 
period of time, commuters travel daily into and out of the host region.

For our purposes, the analysis of the impact of migrants on local employment levels may not be directly applicable to commuters. For example, differences in educational levels between resident workers and commuters are typically less pronounced than those between resident workers and migrants. This similarity in educational level (and skills and qualifications) increases the likelihood that commuters are more readily assimilated by the receiving labour market than migrant workers.

\section{From Commuting to Employment: a Theoretical Road Map}

From a macroeconomic perspective, commuters can have a double impact on the employment level of the receiving local labour market. First, commuters may compete in terms of jobs with the locals. That is, commuters may crowd out resident workers from available jobs. In this setting labour demand (i.e. the number of jobs) is usually considered to be fixed. Hazans (2005) finds a negative effect of the number of commuters on local employment in his analysis of the local labour markets (commuting from rural to urban areas) in the Baltic states.

Pierrard (2008) provides an interesting extension, which - on top of the congestion effect allows for a positive externality of the increased availability of workers on vacancy creation (the cost of an open vacancy is lowered by the greater ease of finding workers, thus raising labour demand). Using shocks to commuting costs and population density in neighbouring regions, he finds that the effect of foreign commuting on local employment in Luxemburg (the size of this country creates a situation where most commuters live abroad $^{9}$ ) is small but positive.

A second channel through which commuters may increase local employment is their impact on aggregate demand. In fact, to the extent that commuters shop and carry out their transactions in the receiving labour market, they positively contribute toward higher consumption levels and a higher

$9 \quad$ The neighbouring countries considered are: Germany, France, the Netherlands, and Belgium. 
demand for public services. This possibility is briefly entertained in Hazans (2005) who does not, however, investigate the empirical content of the proposition. The interesting issue of the effect of commuting flows on the optimal provision of public goods in the local economy is addressed by Shields and Shideler (2003). Moving from the perception of commuters as "free-riders" (they use public services that they do not pay for), they develop a model to determine the optimal commuting tax size for Pennsylvania’s municipalities.

The above-mentioned literature underlines that commuters may generate both virtuous and vicious outcomes for the locals, and that, as in the case of migration, complementary and substitution effects may arise. To sum up, with specific respect to employment in the destination region, we expect commuting inflows to have two main contrasting effects on local employment. In fact, commuters may cause new jobs to be created for the locals by raising the demand for goods and services (for example, public transport). At the same time, however, they are likely to crowd out some residents, since they compete with them for the available jobs. The comparison of the findings from Hazans (2005) and Pierrard (2008) highlights that the question which of the two forces will prevail is an empirical one. Consequently, we will put this question to an empirical test, in which commuting effects on labour markets are explicitly modelled. We will first describe the database and variables used by us.

\section{The Database}

Our data set mainly builds on IAB (Institut fur Arbeitsmarkt und Berufsforschung) data on the 439 German NUTS 3 districts (Kreise). The data come from the administrative records of all employed persons in Germany, and cover the period 1996-2005. We have next complemented this 
data set with demographic data extracted from the regional data bank of Eurostat. The available data are summarized in Appendix $1^{10}$.

The data also contain information on the population of working age (15-64), and on labour demand (the number of jobs in a given district $i$, both part-time and full-time). We will refer to the first variable as $W A P_{i}$, and to the second as $J_{i}$. Regional labour demand (the number of jobs in a district) is obtained by counting the number of workers enrolled in the social security system, whose jobs are located in a given district (recorded in the month of June of each year), regardless of where they live.

The data also record the place of residence of workers. Commuter flows between districts are derived by aggregating the information on the place of work and the information on the place of residence $^{11}$.

In fact, the number of workers in a given labour market district $i$ employed in any German district differs from the number of jobs available in $i$, because both out-commuting (people located in $i$ but working in a different German district, denoted by $O$ ) and in-commuting (workers employed in district $i$ who reside somewhere else in Germany, denoted by $D$ ) may occur. Formally, labour demand (the number of jobs $J_{i}$ in a given district $i$ ) is related to employment $\left(R E_{i}\right.$, the number of employed workers resident in a given district $i$ ), as follows:

$$
R E_{i}=J_{i}+O_{i}-D_{i}
$$

The amount of inbound and outbound commuting might be mutually related. For example, in the case of migration, the hypothesis that in-migration in a given country could bring about outmigration by natives (with the same skill composition of immigrants) has been proposed, leading to the idea that the arrival of one immigrant leads to the outmigration of one native. See, for example,

\footnotetext{
$10 \quad$ For the sake of completeness, we note that there is also some information on distances (in km) and travel times (in minutes) between the districts. Air distances are available for the years 2003, 2005 and 2007, and road distances for the years 2003 and 2005. Train travel times are available only for the year 2002 and for districts below a given distance. Car travel times are available for the years 2003, 2005 and 2007.

11 For any given year, all flows from any district to a different one are recorded, but the volume of commuters must be at least 3 .
} 
Card and DiNardo (2000) ${ }^{12}$. Therefore, the effect of inbound commuters outbidding natives does not necessarily turn out to increase local unemployment: residents crowded out may find a new job in another district, thus becoming commuters themselves. We find that the correlation between the inflow rates and the outflow rates over time by district is positive in the majority of cases, 241 districts (with a median value of the correlation of 0.29 ), but the correlation coefficient is negative for a large number of districts too: 198 districts (with a median value of the correlation coefficient of -0.27). On the whole, the sign and magnitude of the correlation coefficients are compatible with a scenario that envisages commuters displacing resident workers in some districts. However, to draw a definitive conclusion, we ought to be able to compare homogeneous groups of workers, where homogeneity refers to skill type and educational attainment (Card and DiNardo, 2000).

Next, since it is recognized in the literature (see, for example, Pierrard, 2008) that the availability of commuters will generate positive labour demand externalities (via the decrease in the cost of opening a vacancy), we will also consider the effect of commuting on the number of jobs in district $I$, and on the demand for local labour (denoted by $R E P_{i}$ ) defined as follows:

$$
R E P_{i}=J_{i}-D_{i}=R E_{i}-O_{i}
$$

12 In this work, the effect of the skill composition of immigrants on the skill composition of natives in a given local labour market is analysed. The assumption made is that migration affects wages only through the skill composition of the labour force. Moreover, this relationship is informative about the location decision of natives in response to migration. The previous skill composition of migration flows is used as an instrument. In contrast to most of the previous literature, they conclude that migrants do not outbid natives. As a result, changes in the skill composition of migration flows lead to changes in the skill composition of the workforce at large. They are also of the opinion that, instead of the crowding-out of natives, different adjustments to migration (for example, in the industry composition) take place.

A related topic is discussed by Mocetti and Porello (2008), who analyse how immigration to Italy may affect native internal mobility, given labour market adjustments related to these two contrasting effects. They stress the importance of the skill composition of the labour force: since migrants are likely to be considered low-skilled workers, they are likely to be substitutes for low-skilled workers, and complementary for high-skilled ones (therefore leading to positive effects for the former, and negative effects for the latter). Since a reverse causality also holds (migration is affected by labour market outcomes of the host country), they use two different kinds of instruments to solve the endogeneity issue arising: distance from gateways to Italy, and (as in the case of Card and DiNardo, 2000) the existence of previous enclaves of immigrants. The results suggest that the net population of natives (given by the difference between inflows and outflows) is slightly decreased for unskilled workers (seen as substituted by immigrants), while it is increased for skilled workers (because of complementary effects). 
Finally, given the possibility of economies of scale (market-size effect) on labour creation and employment, we will rescale the variables in Equations [1] and [2] by the regional working age population in order to obtain employment (and labour demand)-to-population ratios.

Consequently, the variables of interest in the empirical analysis will be:

- the employment-to-population ratio $\left(E P O P_{i}\right.$ hereafter), calculated as the ratio of regional employment $R E_{i}$ (number of employed workers resident in $i$ ) to the working age population of the district. For this variable, we will assess the net impact of inbound commuter flows (whether they crowd out local workers or not);

- local labour demand density (the number of jobs divided by the regional working age population, denoted by $\left.L D D_{i}\right)$. For this variable, we will then assess to what extent inbound commuters generate a labour demand externality (through the reduction in the cost of opening a new vacancy);

- local occupancy rate (denoted by $L O R_{i}$ ), defined as the fraction of local labour demand filled by workers residing in the same region. As with the previous variables, the effect of incommuting will be considered in this variable.

The three variables under investigation are thus defined as follows:

$$
\begin{aligned}
& E P_{i} \Theta \frac{R}{P} \frac{R}{P} ; \\
& L D D=\frac{J_{i}}{W A_{i} P} \\
& L O R=\frac{R E P}{J_{i}} .
\end{aligned}
$$


The analysis of the impact of inbound commuter flows on each of the above-mentioned variables will be carried out in a stepwise commuting impact model presented in the next section.

\section{The Impact of Commuter Flows on the Receiving Region's Labour Market: Empirical Results}

\subsection{Employment-to-population ratios: overall results}

The aim of this paper is to assess how inbound commuting flows affect labour market outcomes for natives in the receiving district. Specifically, we will now analyse the effect of inbound commuting flows on the employment of resident workers. We will consider the three measures of labour market outcomes introduced in Section 4: the employment-to-population ratio; the demand for local workers; and the local occupancy rate (as defined in Section 4). All these variables are measured at the district level.

The analysis will be carried out by using fixed-effects panel models, because of the presence of unobserved district characteristics that are relatively stable over time (such as the importance of different industries, average wage levels, educational levels, skills, and age composition of the workforce, etc.) that may also be correlated with the regressors ${ }^{13}$. Furthermore, a time fixed effect accounting for the evolution of overall economic conditions has been included as well.

We first address the impact of commuting on the overall probability of employment of resident workers using the following model:

$$
E P O P_{i t}=\alpha D_{i t}+\beta G D P_{i t}+\delta D E N S_{i t}+\eta_{i}+\lambda_{t}+\varepsilon_{i t},
$$

where subscript $i$ denotes districts, and subscript $t$ denotes time. $E P O P_{i t}, D_{i t,} G D P_{i t}$ and $D E N S_{i t}$ are thus related to district $i$ at time $t$. In particular, EPOP it is the employment-to-population ratio (we will take its logit transformation, being the level variable ranging between 0 and 1$)$; $D_{i t}$ is the (log

$13 \quad$ We have performed all the analyses using both fixed- and random-effect specifications. However, Hausman specification tests always (when feasible) appeared to support the fixed-effect specification. 
of) total number of inbound commuters divided by 1,000; GDP is the value added (at current prices, taken in its logarithmic transformation) ${ }^{14}$; and $D E N S_{i t}$ is the population density (number of inhabitants per 1,000 square metres). The parameters $\eta$ and $\lambda$ are fixed effects relating to district and time (which may be correlated with the regressors), while $\alpha, \beta$, and $\delta$ are coefficients to be estimated. Finally, $\varepsilon$ is a random error term that follows the usual OLS assumptions.

The impact of commuter flows on the local employment-to-population ratio is then expressed by $\alpha$. A positive value would suggest that the effect of larger commuter flows through aggregate demand (or through the labour market externality) tends to outweigh the substitution effect. In this sense, larger inbound commuting flows increase the probability of employment for workers residing in the receiving region (remember that the inflow of commuters and the outflow of commuters in each district are positively correlated).

The results from the regression can be found in Table 1, column 1 . On the whole, we find a positive impact of the inflow of commuters on the employment-to-population rate ${ }^{15}$. Thus, the probability of employment is enhanced in regions with large inflows of commuters. To the extent that the total employment results of commuting flows on the receiving district can be classified into the two contrasting effects described in Section 2, the positive employment effect due to aggregated demand tends to dominate the substitution effect, leading to the observed overall positive result.

\subsection{Aggregate demand and the labour demand externality}

We next turn to the effects of inbound commuter flows on labour demand. To assess the importance of this phenomenon, we use the following two-way fixed-effect regression:

\footnotetext{
$14 \quad$ Elhorst (2003) and Perugini and Signorelli (2007) stress the importance of institutional variables (such as trade union density, expenditure on active and passive labour market policies, and the burden of taxes on labour). Unfortunately, institutional variables are only available at a national level, and, therefore, we had to omit them, because they will be collinear with the year fixed effect.

15 The result is robust to the specification of the employment-to-population ratio, and to different specifications of the inflow. The positive significant result is also obtained in a linear probability model. In addition, the positive (and significant) coefficient is maintained when the inflow of commuters is in linear form, and when the lagged value of the logarithm of the inflow of commuters is used in place of the contemporaneous (log) commuter flow.
} 


$$
L D D_{i t}=\gamma D_{i t}+\beta G D P_{i t}+\delta D E N S_{i t}+\eta_{i}+\lambda_{t}+\varepsilon_{i t}
$$

where $L D D_{i t}$ is the local labour demand density as defined in Section 3 (we did not use the logit transformation because $L D D$ is not bound between 0 and 1 ); $\gamma$ is a parameter to be estimated; and all the remaining symbols retain their meaning. In this case, the parameter of interest is $\gamma$. A positive value of this coefficient would suggest that, ceteris paribus, districts with larger commuting flows tend to have a larger number of jobs (after controlling for GDP and population density). In this case, the interpretation would be that either an aggregate demand effect or a labour demand externality is presently at work. The estimates are presented in Table 1, column 2.

The effect of the flow of inbound commuters on the number of jobs in the district is positive and significant ${ }^{16}$. That is, the higher the flow of inbound commuters, the higher the number of jobs in a region. As anticipated above, there are two possible explanations for this result.

The first is that commuter flows augment the labour supply for jobs located in a given district, thus lowering the cost of opening a vacancy.

Table 1: Two-way fixed-effect estimates (time- and county-fixed effect) of the effect of commuter flows

\begin{tabular}{lccc}
\hline VARIABLES & $(1)$ & $(2)$ & $(3)$ \\
\hline Lninflow & logitEPOP & LDD & logitLOR \\
\hline Lngdp & $0.247^{* * *}$ & $0.179^{* * *}$ & $-0.585^{* * *}$ \\
\hline & $(0.011)$ & $(0.004)$ & $(0.011)$ \\
\hline Denspop & $-0.055^{* * *}$ & 0.005 & $-0.128^{* * *}$ \\
\hline & $(0.015)$ & $(0.005)$ & $(0.015)$ \\
\hline & $0.278^{* * *}$ & $0.016^{* * *}$ & $0.242^{* * *}$ \\
\hline
\end{tabular}

Standard errors in parenthesis; *** significant at the $1 \%$ level, ** significant at the $5 \%$ level, *significant at $10 \%$ level

16 As in the case of $E P O P$, positive and significant coefficients are also obtained when a linear specification is used for the inflow of commuters, and when the lagged (log) commuter inflow is used. 
A second explanation would rely on a version of Okun's law stressing the derived nature of labour demand: to the extent that commuters need infrastructure and spend and shop in the district where they work (and not in the district where they live), they generate additional demand for goods and services. Both these processes would lead to additional job creation. Unfortunately, with the data at hand, we are not able to tell which of the two hypotheses is more relevant.

\subsection{The local occupancy rate}

Finally, we turn to the proportion of local jobs held by resident workers: the local occupancy rate. The following two-way fixed-effect regression model has been employed to gauge the effect of inbound commuter flows on the local occupancy rate:

$$
L O R_{i t}=\pi D_{i t}+\beta G D P_{i t}+\delta D E N S_{i t}+\eta_{i}+\lambda_{t}+\varepsilon_{i t}
$$

where $L O R_{i t}$ denotes the logit transformation of the local occupancy rate (i.e. the fraction of local jobs filled by residents in district $i$ at time $t$ ); $\pi$ is a parameter to be estimated; and all the remaining symbols retain their meaning.

The parameter of interest in this equation is $\pi$ : a positive value would imply that, as the commuter flow increases, so does the fraction of jobs held by resident workers.

In this case, we find a negative effect of the inflow of commuters on the local occupancy rate ${ }^{17}$. Districts with a higher inflow of commuters tend to have a lower local occupancy rate. That is, a lower percentage of the jobs located in the district are held by workers who also live in the district itself. The negative sign implies that the likelihood of a resident worker filling a job created by the additional demand derived by the presence of commuter flows is, on average, lower than the share of resident jobs held by resident workers. This should not come as a surprise: the new vacancies

17 For this variable, similar results (in terms of sign and significance) are also found when the linear specification is chosen for the inflow of commuters and for the local occupancy rate (linear probability models), and when lagged values are considered. 
opened might very well be filled by commuters. All empirical results are presented in Table 1, column 3.

\subsection{Commuter flows and employment: synthesis}

All in all, we have found a positive impact of commuter flows on job creation, either through a labour demand externality (by reducing the cost of opening a vacancy, commuters increase labour demand in neighbouring districts) or through an aggregate demand effect. In addition, we found a positive impact of inbound commuter flows on the employment-to-population ratio of receiving districts. Finally, we found that higher commuter flows tend to reduce the local occupancy rate: the share of resident jobs occupied by resident workers.

Clearly, it should be recognized that a reverse causation may also exist: a strong economy and related strong job creation might also increase commuter flows. In the scientific literature (see Section 1), commuting is often considered as the outcome of, among others, variables related to the labour market ${ }^{18}$. In particular, the employment rate of a region may affect the propensity to commute to it.

In fact, we may not directly regress the relevant employment variable on commuting flows to identify a causal effect. The most natural way to eradicate this source of bias is to use an Instrumental Variable (hereafter IV), i.e. a variable correlated to the endogenous regressor (in our case, the commuting flows), but exogenous with respect to the dependent variable (here, employment rate). For a review on the use of IVs and formal definitions, see Pearl (2000) and Angrist and Krueger (2001).

Given the limitations in our database, the choice of $I V s$ is rather limited. The instrument we use here is built on car density: the number of cars per 1000 inhabitants. In particular, car density in the origin districts is chosen in this context as a suitable IV: while it is correlated with the outflows of

18 See, for example, Shields and Swenson (2000) and Hazans (2003). 
commuters from the origin districts $k$ (as is well known from the 4-stage transport generation model), it does not affect employment levels in the receiving district. Consequently, we may use car density in district $k$ as an $I V$ for the commuting flows from $k$ to district $i$.

We will proceed in three steps. In the first step we regress the total outflow of commuters from each district (regardless of their destinations) on car density, and on districts and time effects using the following model:

$$
\log \left(O_{j t}\right)=\theta C D_{j t}+\eta_{j}+\lambda_{t}
$$

where $O_{j t}$ is the total outflow of commuters from district $j$ at time $t$; $C D_{j t}$ denotes the car density of district $j$ at time $t$; and $\eta_{j}$ and $\lambda_{t}$ are the fixed effects for district and time, respectively.

In the second step, following the approach adopted in Mocetti and Porello (2008) in their analysis of Italian immigration flows, the fitted values from the regression are allocated to the individual origin-destination links using a fixed set of weights obtained from data not included in the sample data. For each district $k$, we calculate the fraction of total commuters working in district $i$ in year 1996, and use this fraction as a weight to allocate outflows to the origin-destination pair $(k, i)$, and repeat the exercise for each link. In the third step, we sum all the inflows to district $i$ in order to obtain the instrument for total commuter inflows used in the regression analysis.

The results from the $I V$ estimates are shown in Table $2^{19}$ and appear to be robust to the model specification adopted $^{20}$. Compared with the OLS results in Table 1 , the coefficients of the $\log$ inflow increase substantially. In the case of the Local Occupancy Rate, they even change sign.

\footnotetext{
19 Regressions are performed using fixed-effect models. Tests on under-identification (Cragg-Donald Wald $F$ statistics) and weak-identification (Andersson LM statistics) have been performed, together with $F$-tests on the significance of instruments in the first-stage regression. All tests assess the relevance of instruments. In particular, the F-test value for the logarithm of inflows is 76.19.

20 We tried the level of the dependent variable instead of its logit transformation in the case of EPOP and LOR: the results on the sign and significance of the coefficients related to inflows do not change.
} 
Table 2: Two-way fixed-effect estimates (time- and county-fixed effect) of the effect of commuter flows using an instrumental variable

\begin{tabular}{lccc}
\hline & $(1)$ & $(2)$ & $(3)$ \\
VARIABLES & logitEPOP & LDD & logitLOR \\
\hline \multirow{2}{*}{ Lninflow } & & & \\
& $0.971^{* * *}$ & $0.364^{* * *}$ & $0.524^{* * *}$ \\
Lngdp & $(0.112)$ & $(0.034)$ & $(0.148)$ \\
& $-0.250^{* * *}$ & $-0.044^{* * *}$ & $-0.426^{* * *}$ \\
Denspop & $(0.037)$ & $(0.011)$ & $(0.049)$ \\
& $0.109^{* * *}$ & $-0.027^{* *}$ & -0.018 \\
& $(0.036)$ & $(0.011)$ & $(0.047)$
\end{tabular}

Standard errors in parenthesis; ${ }^{* * *}$ significant at the $1 \%$ level, ** significant at the $5 \%$ level, *significant at $10 \%$ level

We have also tried a different model specification to deal with the endogeneity issue. In fact, the reverse causation problem may also arise with respect to GDP. On the one hand, GDP is measured as the demand for goods and services, therefore inducing demand for labour too (in order to produce the demanded goods). On the other hand, GDP is the sum of all incomes, including labour income. Consequently, the higher the employment rate in a district, the higher the wage bill and, hence, GDP.

In the spirit of much panel literature, we have chosen the lagged values of GDP as an instrument. This is a valid instrument, to the extent that shocks work out their effects in just one period and do not carry over into the future. The results of the double instrument models are largely comparable to those presented in Table $2^{21}$.

\section{Commuter Flows and Employment: Discussion and Conclusion}

This paper has aimed to assess the importance of commuter flows for regional employment. To the best of our knowledge, this is the first time that the aggregate effects of commuting flows have

21 The coefficients remain significant, with positive signs and are of comparable magnitude, and the instruments are still relevant in the first-stage regression. 
been investigated. To the best of our knowledge, the present paper offers an original perspective on the importance of regional mobility, showing novel results on the impact of commuter flows on employment in the receiving districts. We have highlighted three channels through which commuter flows could affect employment in the receiving districts: a crowding-out mechanism, and two labour demand effects. The crowding-out mechanism involves a negative relationship between commuter flows and employment in the receiving district, to the extent that they substitute for resident workers (commuters and locals compete for a fixed number of jobs). The two labour demand channels imply a positive relationship between inbound commuter flows and employment in the receiving district, mediated by an increase of jobs (labour demand). First, commuter flows may generate a positive labour demand externality: they lower the cost of opening a vacancy, thus increasing the stock of jobs in the receiving labour market. Second, they have a positive impact on aggregate demand: commuters need infrastructure (which must then be built and manned) and buy goods and services in the receiving districts, thus stimulating the employment there. To the extent that these two effects hold, they tend to increase employment in the receiving districts.

The overall picture emerging is a positive one: commuter flows tend to increase employment and job creation in the receiving region. There appears to be a significant relationship that is robust to specification form, and that survives the Instrumental Variable procedure too. The results open rich and new research avenues. In fact, while prima-facie evidence suggests that competition between commuters and resident workers might be an issue in the German labour market ${ }^{22}$, the overall employment effect appears to be positive.

Our results suggest that the positive externalities are indeed at work, although we are not able to assess their magnitude (which is likely to be small) for the logit transformation. Clearly, the use of a more straightforward instrument, directly (rather than indirectly) related to commuter flows on a given link, would increase the degree of precision in the measurement of the size of the positive externality effect found.

22 Lack of controls for skill levels or educational attainment in the data set prevents us from being more precise. 
We finally note here that, with respect to the two labour demand channels (labour demand externality and aggregate demand) through which commuter flows positively affect employment, additional data would be required to tease out their relative importance.

Clearly, this first analysis is not yet entirely conclusive, and therefore we now suggest several ways in which our analysis could be extended.

A first class of recommended improvements concerns the instruments to address the endogeneity issue. In fact, this point would require the statistical availability of better instruments, such as changes in regional fiscal policies affecting the tax regimes that influence commuting costs (or, if existing, wage compensation for commuting). Then, with a precise measure of the impacts of commuting on the employment rates at hand, also policy implications could be assessed. In particular, we would then be able to evaluate the effects of policies meant to encourage commuting by increasing accessibility (for instance, by decreasing commuting time and cost).

A second suggested extension concerns the symmetry of the relationship between employment and commuter flows. If inbound commuter flows generate employment in the receiving district, they are likely to decrease employment in the region of origin. However, the relationship is not necessarily symmetric, if, for example, the skill composition that characterizes commuter flows matches the skill needs of the receiving district but differs from the skill needs of the district of origin. Therefore, to carry out this type of analysis, additional information on workers' educational attainment and skills would be needed. Moreover, a better description of the skill-mix used by firms (in both the origin and the destination districts) would also be needed.

The third important class of extensions would aim to assess the empirical relevance of the labour demand externality. This could be done by investigating the impact of commuter flows on vacancies and job creation. Job creation could be measured by looking at the number of jobs in new firms, or in employment relationships shorter than one year. An additional issue worth investigating is the heterogeneity in the relationship between commuter flows and regional employment. In fact, such a relationship is likely to be particularly strong in the presence of hubs (in the sense of 
networks of economic activities). To the extent that hubs are geared to systematically use economic resources from outside the region, it is plausible to assume that job creation and the labour demand externality might be particularly strong in hubs, and less so in other districts. An additional source of heterogeneity in the importance of the labour demand externality could derive from the link between job creation and technological progress. As long as technological progress follows a Schumpeterian process of job creation and destruction, the labour demand externality, by increasing vacancy creation, could facilitate technological progress. In this case, it also seems sensible to assume that the labour demand externality might be particularly important for those districts which host technologically advanced firms, able to use vacancy creation to bring about technological innovation.

Finally, as indicated above, a large body of literature exists on the effects of migration on employment in the receiving area. Therefore, in case of availability of data on relocation across districts, we could consider a model where the combined effects of migration and commuting are simultaneously evaluated. Clearly, these extensions, however interesting, are beyond the purpose of the present project, but are listed as promising future research directions.

\section{Acknowledgements}

We wish to thank Anette Haas and Uwe Blien for making the IAB dataset available to us and giving us constructive ideas and suggestions. We are also grateful for comments from Jos van Ommeren and Jan Rouwendal.

\section{References}

Anas, A., and Xiong, K. (2005), The Formation and Growth of Specialized Cities: Efficiency without Developers or Malthusian Traps, Regional Science and Urban Economics, 35 (4), 445-470.

Angrist, J., and Krueger, A. (2001), Instrumental Variables and the Search for Identification: From Supply and Demand to Natural Experiments, Journal of Economic Perspectives, 15 (4), 69-85.

Baye, M., Morgan, J., and Scholten, P. (2006), Information, Search, and Price Dispersion, Working Papers 2006-11. Indiana University, Kelley School of Business, Department of Business Economics and Public Policy.

Birg, H. (1981), An Interregional Population-Employment Model for the Federal Republic of Germany: 
Methodology and Forecasting Results for the Year 2000, Papers of the Regional Science Association, 47 (1), 97-117.

Bode, E. (2006), Commuting, Externalities, and the Geographical Sizes of Metropolitan Areas, Kiel Working Papers 1289. Kiel Institute for the World Economy.

Borjas, G. J. (2003), The Labor Demand Curve is Downward Sloping: Reexamining the Impact of Immigration on the Labor Market, NBER Working Papers 9755.

Card, D. (1990), The Impact of the Mariel Boatlift on the Miami Labour Market, Industrial and Labour Relations Review, 43 (2), 245-257.

Card, D., and DiNardo, J. (2000), Do Immigrant Inflows Lead to Native Outflows? American Economic Review, 90(2), 360-367.

Delayque, M. (1969), The Linkage Effects of Transportation Infrastructure: Tentative Study of the Impact of the Rhone Valley Motorway on the Regional Economy and the Level of Activity. Paris, Ministry of Transport, 85-108.

Diamond, A. P. (1982), Aggregate Demand Management in Search Equilibrium, Journal of Political Economy, 90 (5), 881-894.

Elhorst, J. P. (2003), The Mystery of Regional Unemployment Differentials: Theoretical and Empirical Explanations, Journal of Economic Surveys, 17 (5), 709-748.

Epifani, P., and Gancia, G. A. (2005), Trade, Migration and Regional Unemployment, Regional Science and Urban Economics, 35 (6), 625-644.

Guisan, M. C., and Aguayo, E. (2001), Employment and Regional Development in Germany, Applied Econometrics and International Development, 1 (2), 59-90.

Hazans, M. (2003), Commuting in the Baltic States: Patterns, Determinants and Gains, Working paper B02-2003. ZEI (Centers for Integration Studies, Univ. of Bonn).

Hazans, M. (2005), Does Commuting Reduce Wage Disparities?, Labor and Demography 0509012, EconWPA.

Juessen, F., and Bayer, C. (2005), Convergence in West German Regional Unemployment Rates, ERSA conference papers ersa05p410. European Regional Science Association.

Karlsson, C., Andersson, M., and Grasjo, U. (2006), Knowledge Accessibility and Regional Economic Growth, ERSA conference papers ersa06p93. European Regional Science Association.

Larsen, M. M., Pilegaard, N., and van Ommeren, J. (2008), Congestion and Residential Moving Behaviour, Regional Science and Urban Economics, 38 (4), 378-387.

Lingens, J., and Heining, J. (2006), Social Interaction in Regional Labour Markets, ERSA conference papers ersa06p43. European Regional Science Association.

Longhi, S., Nijkamp, P., and Poot, J. (2009), Regional Economic Impacts of Immigration: A Review, Tinbergen Institute Discussion Paper 09-047/3.

Manning, A. (2003), Monopsony in Motion: Imperfect Competition in Labour Markets. Princeton, NJ: Princeton University Press.

Mocetti, S., and Porello, C. (2008), How does Immigration Affect Native Internal Mobility?, paper presented at the Third Italian Congress of Econometrics and Empirical Economics held in Ancona, 30-31 January 2009.

Mortensen, D. (2003), Wage Dispersion: Why are Similar People Paid Differently. Cambridge, MA: MIT Press.

Östh, J. (2007), Home, Job and Space, Ph.D. thesis. Uppsala Universitet, Minus, Gustavianum, Akademigatan 3.

Pearl, J. (2000), Causality: Models, Reasoning, and Inference. Cambridge, UK: Cambridge University Press.

Perugini, C., and Signorelli, M. (2007), Labour Market Performance Differentials and Dynamics in EU15 Countries and Regions, The European Journal of Comparative Economics, 4 (2), 209-262.

Pierrard, O. (2008), Commuters, Residents and Job Competition, Regional Science and Urban Economics, 38 (6), 565-577.

Pissarides, C.A. (2000), Equilibrium Unemployment Theory. Cambridge, MA: MIT Press.

Ross, S.L., and Zenou, Y. (2004), Shirking, Commuting and Labor Market Outcomes, Working Paper Series 627. Research Institute of Industrial Economics. 
Rossi-Hansberg, E., Sarte, P. D., and O

wens, R. (2009), Firm Fragmentation and Urban Patterns, International Economic Review, 50 (1), 143186.

Rouwendal, J., and van Ommeren, J. (2007), Recruitment in a Monopsonistic Labour Market: Will Travel Costs be Reimbursed?, Tinbergen Institute Discussion Papers 07-044/3.

Shields, M., and Shideler, D. (2003), Do Commuters Free-Ride? Estimating the Impacts of Interjurisdictional Commuting on Local Public Goods Expenditures, Journal of Regional Analysis and Policy, 33 (1), 27-42.

Shields, M., and Swenson, D. (2000), An Industry-level Analysis of Commuting Response to Employment Growth, Journal of Regional Analysis and Policy, 30 (2), 81-94.

Simpson, W. (1992), Urban Structure and the Labour Market: Worker Mobility, Commuting and Underemployment in Cities. Oxford: Clarendon Press.

Stutzer, A., and Frey, B. S. (2004), Stress That Doesn't Pay: The Commuting Paradox, IZA Discussion Papers 1278. Institute for the Study of Labor (IZA).

Südekum, J. (2008), Convergence of the Skill Composition across German Regions, Regional Science and Urban Economics, 38 (2), 148-159.

Thiel, S. E. (2005), A New Model of Persistent Retail Price Dispersion. Available at SSRN: http://ssrn.com/abstract=757357.

Vermeulen, W., and van Ommeren, J. (2004), Interaction of Regional Population and Employment over Time: Identifying Short-run Effects and Equilibrium Adjustment, ERSA conference papers ersa04p256. European Regional Science Association.

Zenou, Y. (2009), Endogenous Job Destruction and Job Matching in Cities, Journal of Urban Economics, 65 (3), 323-336. 


\section{Appendix 1: The Data}

Table A: Descriptive Statistics

\begin{tabular}{|c|c|c|c|c|}
\hline Variable & Mean & Std. Dev. & Min & Max \\
\hline $\begin{array}{l}\text { Log Commuters } \\
\text { Inflow }\end{array}$ & 9.633926 & 0.903771 & 7.714231 & 12.66514 \\
\hline Log GDP & 10.12162 & 0.326322 & 9.352014 & 11.33118 \\
\hline $\begin{array}{l}\text { Population } \\
\text { Density }\end{array}$ & 577.5449 & 709.8221 & 42.2 & 4041.3 \\
\hline $\begin{array}{l}\text { Employment-to- } \\
\text { Population Ratio } \\
\text { (EPOP) }\end{array}$ & 0.494324 & 0.035983 & 0.369854 & 0.591864 \\
\hline $\begin{array}{l}\text { Local Occupancy } \\
\text { Rate }\end{array}$ & 0.659348 & 0.153448 & 0.237207 & 0.917601 \\
\hline $\begin{array}{l}\text { Local Labour } \\
\text { Demand Density }\end{array}$ & 0.489005 & 0.17098 & 0.210787 & 1.399123 \\
\hline $\begin{array}{l}\text { Log Odd } \\
\text { Transformation } \\
\text { (logit) of EPOP } \\
\text { Log Odd }\end{array}$ & -0.02293 & 0.144764 & -0.53285 & 0.371675 \\
\hline $\begin{array}{l}\text { Transformation } \\
\text { (logit) LOR }\end{array}$ & 0.731804 & 0.717439 & -1.16805 & 2.410191 \\
\hline
\end{tabular}

Number of Observations: 1962 